dilatation of the heart which were going on very well, till some foolish effort, perhaps a run of not more than twenty yards, produced a strain of the cardiac muscle which has not been recovered from for weeks; even if the heart has ever reverted quite to its former state ; if, then, angina is due to over-strain of the heart, may not its attacks also each produce a lasting mischief ?

To sum up, then, I wonld say that the presence of increased arterial tension or blood-pressure involves the existence of obstruction at one end, and increased heart-force at the other; that it is important to distinguish between these two conditions; that the form of trace usually considered indicative of high tension really only shows ob. struction, which, while necessarily occurring with it, may also occur by itself; that the measure of the tension is the pressure required to top pulsation in the artery or the circulation in the limb; and that while we should always try to reduce abnormal obstruction, we should but seldom interfere with the tension as such, unless it threaten danger to the heart or vessels.

\section{ON A CASE OF PSEUDO-HYPERTROPHIC PARALYSIS.} Bx JAMES ROSS, M.D., F.R.C.P.Lond.

Assistant-Physician to the Manchester Royal Infirmary.

Mr thanks are due to my friend, Dr. Brown of Burnley, for the notes of the following case of psendo-hypertrophic paralysis.

W. T, aged 10, came under Dr. Brown's care in November 1879. The patient, during infancy, was, according to the statement of his parents, fat and plump, and did not suffer unduly from dentition, or from any of the usual infantile complaints. At twelve months of age he had an attack of inflammation of the lungs, from which he made a good recovery. He began to walk at sixteen months of age, but it was observed that his gait was awkward, and that he was more liable to fall than other children. At five years of age, the parents observed that the boy's arms were somewhat wasted, and, soon afterwards, the flabbiness of his thighs attracted attention; but the calves of his legs were supposed to be particularly well developed and strong. The awkwardness observed in the gait of the boy at an earlier period now became more marked, and the difficulty he experienced in getting up after a fall attracted special attention; but even at this time he could walk three miles into the country, and his condition had not yet caused serious uneasiness to his parents. At six years of age, however, the wasting of his arms and thighs, and the difficulty of walking, had become so apparent, that several medical men were consulted, and the general treatment recommended consisted of cold-water sponging with subsequent strong rubbing with a dry towel, corl-liver oil, and milk and lime-water. But this treatment did not appear to retard the progress of the disease; the wasting of the upper extremities, body and thighs, became more and more manifest, the prominence of the calves became more pronounced, and walking became progressively more difficult. The patient's father and mother were both healthy, and no special proclivity to any nervous disorder could be discovered on either side. This boy was the third child of his parents. One brother died at fourteen months of age from inflammation of the lungs; another brother and three sisters are living, and all are strong and healthy. The father of the patient was a clerk in a manufactory; he was in comparatively easy circumstances, and the boy had been well-fed and clothed, and had never been exposed to cold or damp, or to any particular hardship. The patient was of moderate intellectual capacity; but, although he could read and write a little, his education was neglected for the last three years.

When first seen by Dr. Brown, the patient was an intelligent-looking boy, with cheerful expression of face and fair complexion. His face was round and plump, but there did not appear to be an unusual prominence of any of the facial or masticatory muscles. The muscles of the neck, the scapular muscles, and the serratus magnus on both sides were developed in proportion to the rest of the body, but the latissimus dorsi and the pectoral muscles, especially the sternal portions of the latter, were much wasted. The deltoids on both sides appeared prominent, probably less from an absolute increase in their size, than from the great wasting which all the muscles of the arms had undergone. The muscles of the forearms and hands were not specially affected. The erectores spinæ muscles were of fair volume, but the gluteal muscles were prominent, and felt doughy to touch. The thighs were comparatively slender, but the calves were prominent, and the muscles felt-inelastic and indurated, and became specially dense and hard when contracted. Each arm measured $6 \frac{1}{3}$ inches, the forearm 6 inches, thigh $10 \frac{1}{2}$ inches, and the calf 10 inches. The feet were maintained in the position of talipes : equinovarus; the toes were inverted and overextended with the metatarsophalangeal and flexed at the phalangeal articulations.

The patient was unable to rise from the ground without assistance. When unaided, he could only get on his hands and knees, and eren when he could place both hands on a chair he could only raise his body into semi-erect-attitnde, and so far as to enable him to plant one foot upon the gronind. When assisted to the erect posture, be could stand and walk without extraneous support. On standing, the shoulders were thrown well back, so that a plumb-line let fall from the : most prominent vertebræ cleared the sacrum; the abdomen was protuberant, and the vertebral column was arched, so that a deep concavity was presented by it in the lumbar and lower dorsal regions ; his feet were kept widely apart, and the heels could not be brought to the ground. so that the patient had to balance himself on his toes, which were well turned inwards. On walking, the body was alternately balanced on either leg, so that the gait was waddling. The patellar tendonwere absent, but the cutaneous reflexes were normal. All the muscles reacted to the faradic current; there were no sensory disorders. The general health was good, and the other organs of the body did not present any feature worthy of being recorded.

In the autumn of 1880 I had an opportunity of seeing the patient along with Dr. Brown. He was sitting on a bench, his body being propped up between the wall and a table, on the latter of which he leaned heavily, supporting himself with his elbows. The vertebral column was now arched forwards, the convexity being directed backwards. He was quite unable to stand; and, on an attempt being made to place him in the erect posture, his legs doubled up under him in a perfectly helpless manner. When he was laid on his back on a sofa, with his legs extended, he was unable to raise either heel; but when placed on either side, he could abduct the uppermost thigh, and the glutens medius conld be" felt to contract during this action by the hand placed above the trochanter.

The boy was subsequently admitted to the Manchester Royal Infirmary, under the care of Dr. Leech, and was kept for some time under obscrvation, but during this period no symptom appeared requiring special description. During his residence at the Cheadle Convalescent Hospital, whither he was sent from the infirmary, both his father and mother died after a short illness, and the patient was subsequently transferred to the care of a sister, living at Burnley. The patient gradnally became more and more helpless, but was able, almost to the last, to sit in a chair, his body being propped up between the back of the chair and a table. His face became plumper, the temporal and masticatory muscles being manifestly hypertrophied. On April 6th, 1882, he was seized with a severe attack of diarrhœea and vomiting, accompanied by great prostration, and he died from exhaustion early on the morning of April 9th.

Post mortem Examination.-The post mortem examination was conducted by Drs. Brown and Mackenzie, and myself; thirty-two hours after death. The body was placed with the face downwards soon after death, and post mortem lividity was well marked on the anterior surface of the body. Post mortent rigidity was well pronounced, and even the wasted muscles of the upper extremities presented some degree of rigidity. The most prominent part of the calves of the legs measured, each, $9 \frac{1}{4}$ inches; the middle of the thighs, each, $10 \frac{1}{4}$ inches; the middle of the upper arms, each, 53 inches, and the thickest part of the fore-arms, each, $5 \frac{3}{4}$ inches. The subcutaneous fat was $\frac{1}{2}$ inch thick over the calves of the legs, and $\frac{3}{4}$ inch over the gluteal region, while there was very little subcutaneons fat in the lumbar and dorsal regions, but it was more abundant in the back of the neck. The gluteal muscles were of a pale yellow hue, with the slightest perceptible pink tinge. The conversion of these muscles into fat was so complete, that almost every appearance of muscular structure was lost. The gastrocnemii had more of the pink tinge than the gluteal muscles, and also presented more of the appearance of muscular structure. The erectores spinæ muscles were much wasted, and of a pale colour, but they were by no means so much changed in appearance from healthy muscles as either the gluteal muscles or the gastrocnemii. The scapular muscles were considerably altered, the supraspinati being nearly as much changed as the glateal muscles. The muscles of the back of the neck were wasted, but presented almost the normal colour and texture of muscle. The latissimi dorsi muscles were thin and pale, and more like fibrous membranes than true museles. The brain and spinal cord did not present any abnormal appearances to the naked eye. The spinal cord was placed in a 2 per cent 
solation of ammonium bichromate, and reserved for microsicopical examination. Portions of the diseased muscles, and of the sciatic nerve, ind the first cord of the brachial plexus, were alsoreserved for microscopical examination. The lungs were healthy. The heart was soft and flabby, and its cavities were somewhat dilated. The right side of the heart was full of blood: and the left side empty. The walls of the left ventricle were one half inch in thickness; they were of a pale yellow colour, friable, and easily torn. The walls of the auricles were thin, and their external surfaces were covered with a layer of fat. The large intestines, and the lower half of the small intestines, were distended with hard fecal matter. A small quantity of a purulent fluid was found in the pelvis of the right kidney, but the kidneys were in other respects normal. The liver presented a normal appearance.

A microscopical examination showed that every muscle of the body, even those which appeared almost normal to the naked eye, had undergone extensive changes. In the muscles which were most changed, like the gluteal muscles, scarcely anything but fat-cells and bundles of a wavy fibrous tissue could be discovered with the microscope. But in those muscles which were least altered to the naked eye, as the erectores spinæ, the fat-cells were much less abundant, but the muscular fibres were separated from one another by an interstitial connective tissue, consisting of parallel fibres, in the midst of which numerous elongated nuclei and cells were embedded. The muscular fibres themselves were greatly altered; they were, as a rule atrophied, some of them being greatly reduced in size. The nuclei of the saxoolemma were much increased in number, but the transverse striation remained well marked, even in fibres otherwise much altered. The fibres themselves did not appear to have undergone fatty degeneration. A large number of the fibres of the cardiac muscles were atrophied, and were in many places widely separated by interstitial connective tissue.

Numerous sections from different elevations of the spinal cord were made by Mr. A. H. Young, Pathological Registrar to the Infirmary, but no evidence of disease could be detected in them. Special attention was directed to the examination of sections from the lumbar enlargement, the dorsal region, and the cervical enlargement on a level with the fifth and sixth cervical nerves. No changes could be detected in either the sciatic nerve or the first cord of the brachial plexus.

Remarks.-It is not yet determined whether the disease of the muscles in pseudo-hypertrophic paralysis is to be regarded as primary, or as secondary to a lesion of their spinal trophic centres. In deciding this question all cases in which a careful microscopical examination of the tissues failed to be made, and all cases, like that offBarth, which were not undoubted examples of this affection, are of no account. A patient of Duchenne's, who died in 1871, from an intercurrent affection while the subject of advanced pseudo-hypertrophic paralysis, is the first case in which the tissues were subjected to a thorongh microscopical examination. Portions of the spinal cord were forwarded to Charcot, Vulpian, and Lockhart Clarke, but these competent observers failed to discover any morbid changes. Post mortem examinations have also been made by Kesteven, $f$ Brieger,ł Bay, $\$$ and Schultze,\| and, although slight changes have been described as having been fonnd in the spinal cord in some of these cases, yet the ganglion cells of the anterior were reported healthy in all of them.

In 1874 , a case of the disease was reported by Drs. Lockhart Clarke and Gowers, 9 in which "varied and extensive" lesions were found scattered throughout the entire length of the cord, " the most extensive lesion being found in the lowest part of the dorsal region, where in each lateral grey substance was an area of disintegration, amounting to an actual cavity outside each posterior vesicular column." $* * *$

A case of this disease; in a boy aged 14 years at the time of death, has recently been recorded by Dr. David Drummond, in which decided changes were met with in the spinal cord. The principal changes are briefly described as "disintegration in the lateral grey network of fibres, least marked on the left side, and in the lumbar enlargement, where there was an accumulation of serum, causing

* See Oharcot. "Note sur l'état anatomique des muscles et de la moelle épiniere daris un cas de paralysie pseudo-hypertrophique."-Archives de Physiologie. Mars, 1872, p. 228.

7 Kesteven. Journal of Mental Seience, vol. xv, 1871, pp. 42 and 563.

Brieger. Deuitsches Arch. für Klin. Med., Band xxil, 1878, p. 200.

Bay. Hospitals-Tidende, 1877; Abstr. in Canstatt's Jahresb.

Bohultio. Virchow's Archiv, Band Ixxv, 1879, p. 482.

7 Otarke and Qowers. "On a case of Peoudo-Hypertrophic Musoular Paraly:

is."- Medico-Chirurgical Transactions, vol. xlvil, isf4. the, cord to bulge out laterally."*. These changes are on the whole, as the author remarks, more or less similar to those observed by Drs. Lockhart Clarke and Gowers. With reference to.Dr. Drum. mond's case, however, it must be remarked that extensive changes were only found in one lateral half of the cord, but, inasmuch as the muscular disease was equally pronounced on both sides of the body the essential lesion, if there be such, must be sought in the minor alterations of the right, and not in the major alterations of the left half of the cord. Dr. Drummond states that, "throughout the entire cord the anterior cornual cells appeared to be numerous and normal," and as these cells are supposed to be the trophic centres of the muscles, this case can hardly be quoted in favour of the theory of the nervous origin of the disease. It is only right to add that Dr. Drummond himself is very guarded in his inferences.from the appearances described by him. "I do not mean to assert confidently" he says: "that this lateral disintegration or tearing was of pathological significance; it may have been due to the manipulation, but I am inclined to think otherwise."

In 1880, Dr. Milner Moore, of Coventry, described three cases of pseudo-hypertrophic paralysis as occurring in a family of seven children. The eldest of those affected, $\mathrm{a}$ boy aged 15 years, died recently and the spinal cord was sent to Dr. Byrom Bramwell for examination. Dr. Bramwell discovered "a curious alteration in the shape of the right lateral half of the cord, and in the arrangement of its grey matter, which reached its highest development in the middle of the cervical enlargement." $\dagger$ This deformity, however, was unilateral; it was evidently congenital and cannot be regarded as an essential part of the morbid anatomy of pseudo-hypertrophic paralysis. The other changes described are "collections of leucocytes and patches of inflammatory softening around the blood vessels,"chiefly distributed throughout the grey matter in the cervical region. But if these collections of leucocytes are to be regarded as evidence of any disease ther must be looked upon as indicating a more or less acute process, and cannot certainly be regarded as evidence of a chronic and progressive disease extending, as in this case, over a period of at least eight years. In the case of a boy, under the care of Dr. Leech, the subject of pseudo-hypertrophic paralysis from early infancy, who died at 10 years of age, I had, through Dr. Leech's kindness, an opportunity of examining the spinal cord. I found changes in the cord $\ddagger$ more or less similar to those described by . Drs. Lockhart Clarke and Gowers; and a case has recently been described by Pekelharing, in which kindred alterations were obserred.\$ In Dr. Leech's case, the patient died during hot weather, and the post mortem examination was not made until thirty-six hours after death, and the hardening of the cord for microscopical purposes was not satisfactory. But, in the case of W.T., the spinal cord was in a good state of preservation at the necropsy, and the subsequent preparation of it by ammonium bichromate has turned out everything that could be desired. I cannot, therefore, doubt for a moment in my own mind, that much greater importance is to be attached to the negative results obtained in the latter case than to the somewhat dubious changes observed in the former, which might be the results of post mortem changes and imperfect preservation. And, contrary to all my prepossessions, I am constrained to decide in favour of the theory which regards pseudo-hypertrophic paralysis as a primary muscular disease.

It is also worthy of notice that, the sciatic nerve, which supplies muscles in the lower extremity, that were deeply involved in the disease, and the first cord of the brachial plexus, supplying the deltoid, biceps, brachialis anticus and supinator longus, some of which were greatly atrophied, presented a perfectly normal appearance, not a single diseased nerve-fibre being discovered after the most careful search. It would appear, therefore, that the disease in the muscles did not in this case give rise to a secondary ascending neuritis, as Friedreich assumes to occur in progressive muscular atrophy in order to account for the changes which have been observed in the spinal cord in that disease. That the ganglion cells of the anterior grey horns of the spinal cord have been found extensively diseased in cases of progressive muscular atrophy is beyond question, but when a"competent observer,']ike Lichtheim, (T) declares that he has found the anterior grey horns quite normal in a case of this disease, such a statement ought not to be passed over too lightly. It is not

* The Lancet, vol. ii., October 15th, 1881, p. 661.

t Bramell, Diseases of the Spinal Cord' 1882

Ross, Diseases of the Nervous System, 1881, vol. ii, p. 206.

Ross, Diseases of the Nervous System, 1881, vol. il, p. 206. bel Prendomuskela

achultze. Bemerkungen über die Pseadohypertrophie der Muskeln. $V$ ir Dchulter. Bemerkangen the

$\checkmark$ Ilchtheim, Deutsches Archiv fir Klin. Med., Band vili, He 
unlikely, to my mind, that two distinct diseases are at present grouped under the name of progressive muscular atrophy, the disease of the muscles being in the one primary, and in the other secondary an affection of the trophic centres in the spinal cord.

With reference to the morbid changes in the muscles in the case of $W$. T., little need be said, inasmuch as they conform accurately to the descriptions of other observers. The annexed wood-cut, from a drawing by Mr. A. H. Young, of altered muscular fibres in Dr. Leech's case will illustrate the changes usually met with. In the least altered muscular fibres the transverse striation is often indistinct, and a considerable increase of the muscle corpuscles is observed (a). In the vicinity of these fibres others may be observed which have undergone every degree of atrophy, while numerous nuclei are always to be seen in their substance $(b$ and $c)$. In some of the fibres which are greatly atrophied, the transverse striation may even be more distinct than in health $(d)$, and then their edges

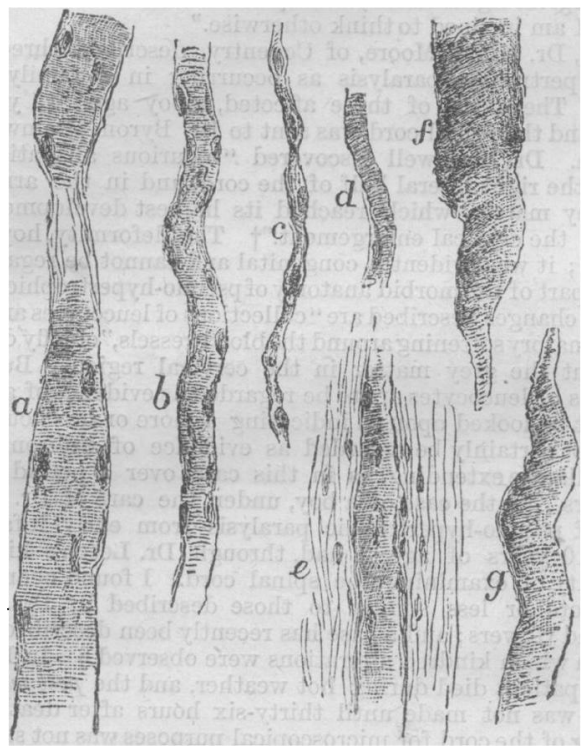

Muscular fibres in various stages of degeneration, from a case of psendo-hypertrophic paralysis.- $a$, Muscular fibres only slightly changed, showing increase of the mula perts of parts greatly atrophied, and presenting nuclei at intervals; $d$, atrophied muscular bre with its transverse striation unusnally distinct; $e$, atrophied cibre sur rounded by a fibrillated connective tissue rich in nuclei ; $f$ and $g$, muscular abres which have undergone a hyaline change, tapering to a point at one end, and sometimes at both ends. Their transverse striation is still faintly visible. appear serrated. The fibres are often surrounded by a mass of a fine fibrillated connective tissue in which numerous elongated nuclei are embedded $(\theta)$. The fibres are still further separated from one another by accumulations of fat-cells, and in muscles like the gluteal muscles in which the disease is very advanced, the muscular fibres and the even newly-formed fibroid tissue have almost completely disappeared, and the structure presents the usual characteristics of an ordinary lipoma. In Dr. Leech's case, I have met in the muscles which were least changed large fibres which had undergone a hyaline change, and which tapered to a point at one, and sometimes at both ends $(f, g)$, but I have not observed similar fibres in the present case. No fatty or granular changes were observed in the muscular fibres themselves; and it would seem as if the alterations in them were secondary to morbid changes in the interstitial connective tissue.

\section{A CASE OF DOUBLE HARE-LIP IN A MAN AGED 32.}

BX WILLIAM ROSE, B.S., F.R.C.S.,

Assistant-Surgeon to King's College Hospital, Burgeon to the Rojal Free Hospital.

LEONARD S., aged 32, living at Wadhurst, Sussex, was admitted into the Royal Free Hospital in June 1881, with double harelip, and complete cleft of hard and soft palate.

The patient's appearance was repulsive in the extreme, and, in the neighbourhood where he lived, he was shunned by most people especially by pregnant women, who feared to look at him, lest their offspring should be similarly affected. He was principally employed in carrying coals; hence his blackened face, coupled with his hideous deformity, gained for him the unpleasant reputation of being an emissary from the infernal regions. The reason for his remaining without operative interference for thirty-two years is partly explained by his devotion to his widowed mother, whom he refused to eave to go to a hospital, and it was only after her death that he consented to have anything done.

The wood-cut $A$, which is copied from a photograph, is a fair representation of the full face, but it does not show the extent of the deformity caused by the projection of the intermaxillary bone,

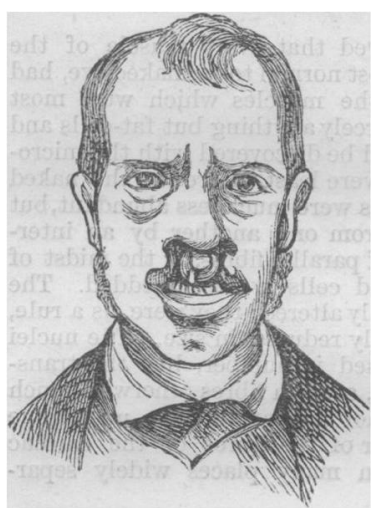

Fig

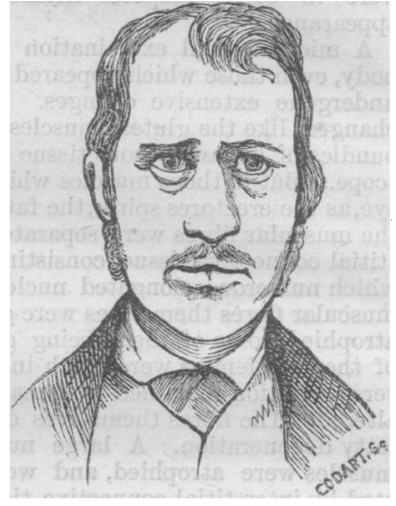

Fig. $n$. containing one central incisor and the stump of another surmounted by the central portion of the upper lip and columna nasi, like a proboscis.

The patient also had a very marked stare, or what I should call a hunted look in his eyes, due, I believe, to the knowledge of his unfortunate appearance, and to the effect he knew it would produce upon those seeing him.

The lower lip was large and fleshy, and hung down, with everted mucous membrane, over which saliva constantly dribbled. The palate was widely cleft, but the edges of the soft parts were thick. Articulation was most imperfect, and it was almost impossible to understand what he said.

Operation.-The patient was chloroformed, and the first steps of the operation were directed to bringing the projecting intermaxillary bone back into position between the maxillæ. To effect this, the mucous membrane was pared off each side of the intermaxillary bone and the edges of the maxillæ. Next, the intermaxillary bone, after the incisor stump had been extracted, was partly cut through, at its junction with the vomer, with bone pliers, applied from behind forwards; by this means it could be pushed back into position, and the above-mentioned raw surfaces brought into contact. A strong silver wire suture was passed through each maxilla across the front of the intermaxillary bone to keep it from slipping out of place.

The lips were then dealt with in the ordinary way, care being taken, in the first place, to dissect each side freely up from the bone. to prevent undue strain when bringing the raw edges together. The central portion of the upper lip continuous with the columna was slightly loosened by dissecting it up from below, its edges pared so as to fit in accurately, like a wedge, with the base upwards, between those of the lateral flaps. Three hare-lip pins were inserted, the two upper transfixing in their passage the central portion, and the parts came easily into position after the twisted figure of eight silk suture had been carefully applied. There was smart bleeding at the time of the operation, but it soon ceased of itself. The pins were removed on the fifth day, and four days afterwards profuse hæmorrhage occurred from both nostrils, and the unionthreatened to break down. The bleeding was with difficulty checked by position, pressure, and application of ice. The remaining central incisor which seemed to be exercising injurious pressure, was extracted, and strapping applied to diminish the tension. But on the following day, as no improvement had taken place, and the tendency to occasional hæmorrhage was still present, I reinserted two hare-lip pins, and applied the twisted suture as before. After this, everything went well, and I withdrew the pins on the fourth day, the lip having firmly united. The intermaxillary suture was taken out on the fourteenth day from the 